\title{
JARINGAN KOMPUTER
}

\author{
INDAH KUSUMA ASTUTI \\ 185100004 \\ Fakultas Komputer \\ indahkusumaastuti.student@umitra.ac.id
}

\begin{abstract}
Jaringan komputer (jaringan) adalah jaringan telekomunikasi yang memungkinkan antar komputer untuk saling berkomunikasi dengan bertukar data. Tujuan dari jaringan komputer adalah agar dapat mencapai tujuannya, setiap bagian dari jaringan komputer dapat meminta dan memberikan layanan (service). Pihak yang meminta/menerima layanan disebut klien (client) dan yang memberikan/mengirim layanan disebut peladen (server). Desain ini disebut dengan sistem client-server, dan digunakan pada hampir seluruh aplikasi jaringan komputer.
\end{abstract}

Dua buah komputer yang masing-masing memiliki sebuah kartu jaringan, kemudian dihubungkan melalui kabel maupun nirkabel sebagai medium transmisi data, dan terdapat perangkat lunak sistem operasi jaringan akan membentuk sebuah jaringan komputer yang sederhana. Apabila ingin membuat jaringan komputer yang lebih luas lagi jangkauannya, maka diperlukan peralatan tambahan seperti Hub, Bridge, Switch, Router, Gateway sebagai peralatan interkoneksinya.

Sejarah jaringan komputer bermula dari lahirnya konsep jaringan komputer pada tahun 1940-an di Amerika yang digagas oleh sebuah proyek pengembangan komputer MODEL I di laboratorium Bell dan group riset Universitas Harvard yang dipimpin profesor Howard Aiken. Pada mulanya proyek tersebut hanyalah ingin memanfaatkan sebuah perangkat komputer yang harus dipakai bersama. Untuk mengerjakan beberapa proses tanpa banyak membuang waktu kosong dibuatlah proses beruntun (Batch Processing), sehingga beberapa program bisa dijalankan dalam sebuah komputer dengan kaidah antrian.

Kemudian pada tahun 1950-an ketika jenis komputer mulai berkembang sampai terciptanya super komputer, maka sebuah komputer harus melayani beberapa tempat yang tersedia (terminal), untuk itu ditemukan konsep distribusi proses berdasarkan waktu yang dikenal dengan nama TSS (Time Sharing System). Maka untuk pertama kalinya bentuk jaringan (network) komputer diaplikasikan..

Kata Kunci : sejarah Jaringan Komputer 


\section{A. PENDAHULUAN}

Perkembangan teknologi komputer meningkat dengan cepat, hal ini terlihat pada era tahun 80-an jaringan komputer masih merupakan teka-teki yang ingin dijawab oleh kalangan akademisi, dan pada tahun 1988 jaringan komputer mulai digunakan di universitas-universitas, perusahaan-perusahaan, sekarang memasuki era milenium ini terutama world wide internet telah menjadi realitas sehari-hari jutaan manusia di muka bumi ini.

Selain itu, perangkat keras dan perangkat lunak jaringan telah benar-benar berubah, di awal perkembangannya hampir seluruh jaringan dibangun dari kabel koaxial, kini banyak telah diantaranya dibangun dari serat optik (fiber optics) atau komunikasi tanpa kabel.

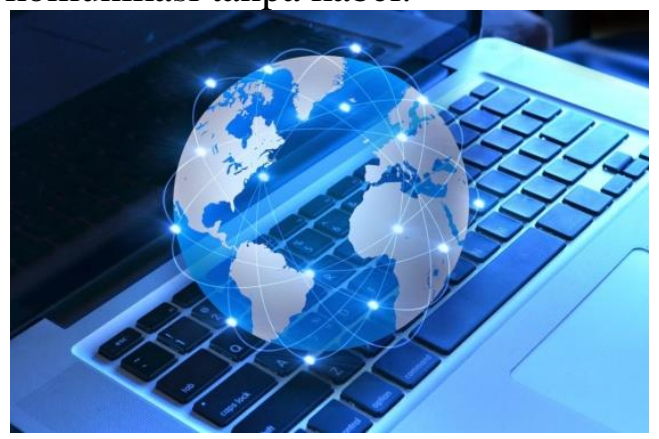

Jaringan komputer membuat perangkat mampu saling terhubung satu sama lain. Misalnya: mentransfer file, Berbagi sumber daya, dan berkomunikasi dengan elektronik hingga

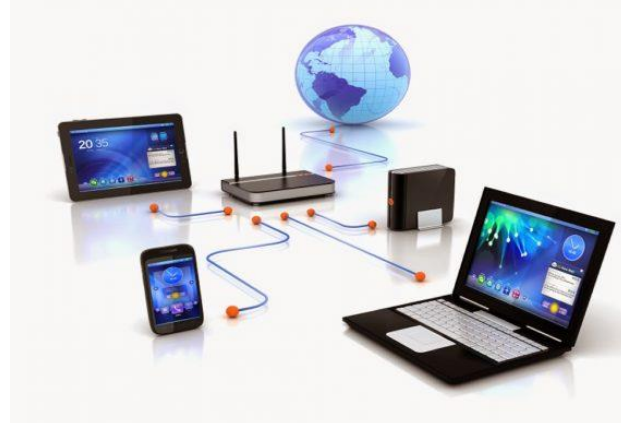

Dengan berkembangnya teknologi komputer dan komunikasi suatu model komputer tunggal yang melayani seluruh tugas-tugas komputasi suatu organisasi kini telah diganti dengan sekumpulan komputer yang terpisah-pisah akan tetapi saling berhubungan dalam melaksanakan tugasnya, sistem seperti ini disebut jaringan komputer (computer network). 


\section{B. PEMBAHASAN / STUDI KASUS}

Jaringan Komputer adalah jaringan telekomunikasi yang memungkinkan antar komputer untuk saling berkomunikasi dengan bertukar data, jaringan komputer dibangun dengan kombinasi hardware dan software. Saat 2 atau lebih komputer saling berkomunikasi atau bertukar data sebenarnya ada bagian-bagian dari jaringan komputer yang menjadi pihak yang menerima atau meminta layanan disebut dengan client dan yang memberikan atau mengirimkan disebut dengan server. Design seperti ini sering disebut dengan Sistem Client- Server.

Komputer yang saling terhubung ini pun harus mempunyai setidaknya 1 kartu jaringan masing-masing yang kemudian dihubungkan melalui kabel maupun nirkabel sebagai medium transmisi data dan terdapat perangkat lunak sistem operasi jaringan yang akan membentuk sebuah jaringan komputer sederhana. Apabila ingin membuat jaringan komputer yang lebih luas lagi jangkauannya maka di perlukan peralatan tambahan untuk mendukung seperti Hub, Switch, Router, dll.

Ada beberapa jenis jaringan komputer yang sering kita lihat dan di klasifikasikan menurut cangkupan areanya, yaitu:
- LAN (Local Area Network)

- LAN atau Local Area Network adalah konsep yang menghubungkan perangkat jaringan dalam jarak yang relatif pendek. Biasanya di gunakan untuk gedung sekolah, kantor, rumah, dll. Konsep jaringan LAN ini cenderung menggunakan konektivitas tertentu, terutapa Ethernet dan Token Ring.

Ada juga LAN yang menggunakan teknologi jaringan Wireless atau nirkabel dengan WI-FI dan dikenal dengan nama Wireless Local Area Network (WLAN).

- MAN (Metropolitan Area Network)

MAN atau Metropolitan Area Network adalah konsep yang menghubungkan perangkat jaringan dari satu Kota ke Kota lainnya. Jika penggunaan LAN sudah tidak memungkinkan untuk membangun jaringan maka jaringan MAN akan di gunakan, karena cangkupannya lebih besar dari LAN maka MAN menggunakan perangkat khusus dan memerluka operator telekomunikasi yang bertugas sebagai penguhubung antar jaringan komputer.

- WAN (Wide Area Network) WAN atau Wide Area Network adalah konsep yang menghubungkan perangkat jaringan komputer yang mencangkup wilayah super luas dan menggunalan peralatan yang super canggih 
apabila di bandingkan dengan MAN dan LAN.

Konsep Jaringan ini sendiri biasanya digunakan untuk mengubungkan suatu jaringan dari negara satu dengan negara lainnya alias antar negara bahkan bisa juga antar benua. salah satu contoh peralatan super canggih tadi adalah fiber optic dimana pemasangannya ditanam di dalam tanah maupun di bawah laut.

Dalam pembangunan jaringan komputer ini sendiri tidak lepas dari namanya topologi, dimana topologi ini sendiri bisa di bilang sebagai bentuk atau struktur virtual jaringan yang mengacu pada tata letak perangkat yang terhubung walaupun bentuk ini tidak selalu sesuai dengan tata letak fisik sebenarnya dari perangkat jaringan.

Topologi jaringan dapat di kategorikan ke dalam tipe dasar berikut, yakni:

- Topologi BUS

Topologi BUS ini hanya menggunakan satu kabel saja sebagai media komunikasi atau media transmisi dan kabel tersebut menjadi pusat bagi seluruh server yang terhubung. Masing-masing komputer dihubungkan ke kabel utama dengan menggunakan konektor $\mathrm{BNC}$, lalu di akhiri dengan terminator.
Contoh gambar topologi bus;

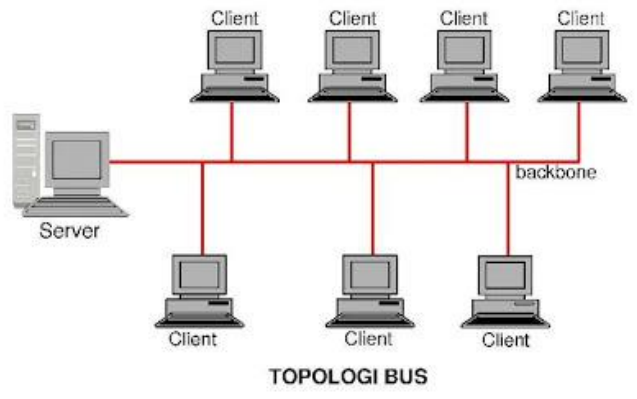

- Topologi RING

Topologi RING adalah topologi jairngan yang rangkaiannya membentuk cincin dan berupa titik yang mana masing-masing titik bagian kanan dan kiri terhubung ke dua titik lainnya sampai komputer pertama dan komputer terakhir terhubung. Titik yang ada pada topologi cincin ini berfungsi memperkuat sinyal di setiap rangkaiannya atau bisa juga di sebut reapeater. dengan metode seperti ini sinyal dan aliran data akan tetap stabil. Arah aliran datanya juga bisa searah jarum jam atau berlawanan dengan jarum jam, tergantung dengan kebutuhan.

Berikut contoh gambar dari topologi Ring

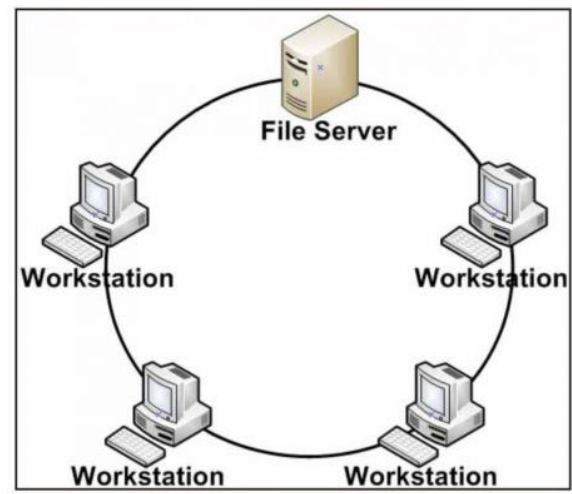


- Topologi STAR

Topologi STAR adalah topologi yang mempunyai 1 penghubung sebagai pusat (HUB atau Switch) dari setiap komputer yang terhubung. Hub atau Switch tersebut posisinya di central dan berfungsi untuk menghubungkan satu komputer ke setiap komputer yang terhubung dan juga menghubungkan komputer ke file server.

Cara kerjanya yaitu apabila ingin bertukar data satu sama lain maka data itu akan mengalir ke HUB atau Switch terlebih dahulu baru kemudian akan menuju ke komputer yang meminta atau yang akan menerimanya. Berikut adalah contoh gambar dari topologi STAR:

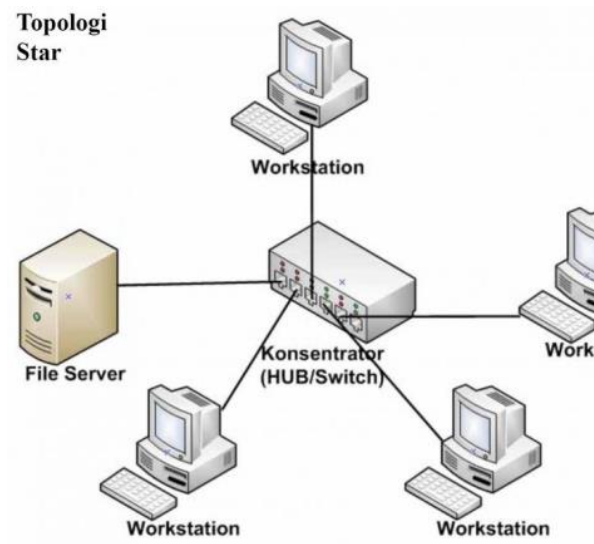

- Topologi Mesh

Topologi Mesh adalah topologi yang jaringannya dapat terhubung satu sama lain secara acak atau tidak teratur. Karena komputer langsung terhubung dengan komputer yang di tuju maka arus data dapat langsung di lakukan dengan cepat tanpa harus melalui komputer lain.

Masing-masing komputer setidaknya memiliki 2 jenis sambungan yaitu pertama kabel yang terhubung dengan komputer lainnya dan kabel lainnya terhubung ke File Server. Topologi ini di sarankan untuk penggunaan yang cangkupannya kecil bukan yang besar karena Topologi ini sangat sulit untuk di kendalikan dan rumitnya dalam mengatur sambungannya

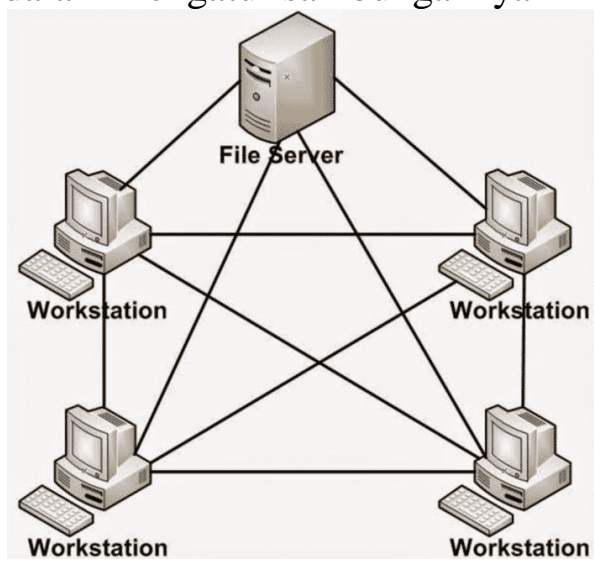

- Topologi Tree

Topologi Tree adalah Topologi yang bertingkat dan hierarki antar koneksi menggunakan Hub atau Switch sebagain media transmisinya dan masing-masing dari hub atau Switch tersebut terhubung dengan file Server.

Topologi Tree sebenarnya kombinasi dari Topologi STAR dan Topologi BUS namun yang membedakannya adalah 
topologi tree ini terdapat banyak Hub ata Switch dalam jaringan dan sistem hierarkinya.

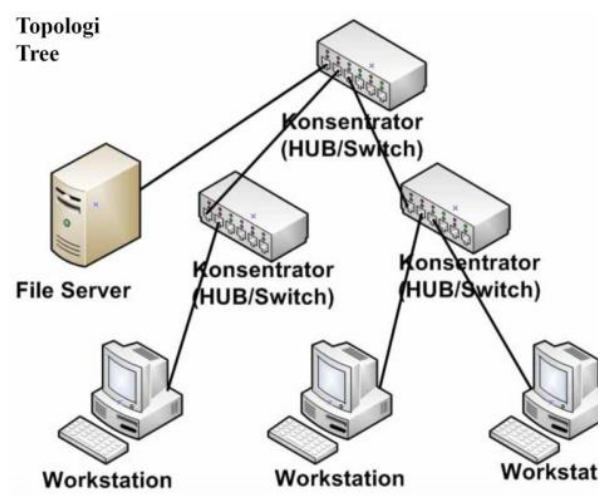

C. ID SECURITY

QWTD4452377-ASP-5244166

\section{KESIMPULAN}

Kesimpulan dari materi ini adalah Jaringan komputer (jaringan) adalah jaringan telekomunikasi yang memungkinkan antar komputer untuk saling berkomunikasi dengan bertukar data. Tujuan dari jaringan komputer adalah agar dapat mencapai tujuannya, setiap bagian dari jaringan komputer dapat meminta dan memberikan layanan (service).

\section{E. DISKUSI}

Bagaimana Pendapat Anda Tentang Artikel Ini ?

yuni : Menurut saya artikel ini sangat bagus untuk kita pelajari karena isinya bisa menambah wawasan kita dengan mengenal jaringan komputer

Apakah kelebihan artikel ini? Budiono : Menurut saya artikel ini cukup baik kerena mudah dipahami dan dimengerti di era sekarang yang sangat penting untuk kita tau apa sih itu? jaringan komputer

Apa fungsi artikel ini ? Zalmi : kita dapat memehami konsep dasar dan pengetahuan umum mengenai jaringan computer.

\section{F. REFERENCE}

[1] O. M. Febriani and A. S. Putra, "Sistem Informasi Monitoring Inventori Barang Pada Balai Riset Standardisasi Industri Bandar Lampung," J. Inform., vol. 13, no. 1, pp. 90-98, 2014.

[2] A. S. Putra, "Paperplain: Execution Fundamental Create Application With Borland Delphi 7.0 University Of Mitra Indonesia," 2018.

[3] A. S. Putra, "2018 Artikel Struktur Data, Audit Dan Jaringan Komputer," 2018.

[4] A. S. Putra, "ALIAS MANAGER USED IN DATABASE DESKTOP STUDI CASE DB DEMOS."
A.
$\mathrm{S}$.
Putra, "COMPREHENSIVE SET OF PROFESSIONAL FOR DISTRIBUTE COMPUTING." 
[6] A. S. Putra, "DATA ORIENTED RECOGNITION IN BORLAND DELPHI 7.0."

[7] A. S. Putra, "EMBARCADERO DELPHI XE 2 IN GPUPOWERED FIREMONKEY APPLICATION."

[8] A. S. Putra, "HAK ATAS KEKAYAAN INTELEKTUAL DALAM DUNIA TEKNOLOGY BERBASIS REVOLUSI INDUSTRI 4.0."

[9] A. S. Putra, "IMPLEMENTASI PERATURAN

PERUNDANGAN UU. NO 31 TAHUN 2000 TENTANG DESAIN INDUSTRI BERBASIS INFORMATION TECHNOLOGY."

[10] A. S. Putra, "IMPLEMENTATION OF PARADOX DBASE."

A. S Putra "IMPLEMENTATION OF TRADE SECRET CASE STUDY SAMSUNG MOBILE PHONE."

[12] A. S. Putra, "IMPLEMENTATION

PATENT FOR APPLICATION WEB BASED CASE STUDI WWW. PUBLIKLAMPUNG. COM."

[13] A.

S. Putra, "IMPLEMENTATION SYSTEM FIRST TO INVENT IN DIGITALLY INDUSTRY."

[14] A. S. Putra, "MANUAL REPORT \& INTEGRATED DEVELOPMENT

ENVIRONMENT BORLAND DELPHI 7.0."

[15] A. S. Putra, "PATENT AS RELEVAN SUPPORT RESEARCH."
[16] A. S. Putra, "PATENT FOR RESEARCH STUDY CASE OF APPLE. Inc."

[17] A. S. Putra, "PATENT PROTECTION FOR APPLICATION INVENT."

[18] A. S. Putra, "QUICK REPORT IN PROPERTY PROGRAMMING."

[19] A. S. Putra, "REVIEW CIRCUIT LAYOUT COMPONENT

REQUIREMENT ON ASUS NOTEBOOK."

[20] A. S. Putra, "REVIEW TRADEMARK PATENT FOR INDUSTRIAL TECHNOLOGY BASED 4.0."

[21] A. S. Putra, "TOOLBAR COMPONENT PALLETTE IN OBJECT ORIENTED PROGRAMMING."

[22] A. S. Putra, "WORKING DIRECTORY SET FOR PARADOX 7."

[23] A. S. Putra, "ZQUERY CONNECTION

IMPLEMENTED

PROGRAMMING STUDI CASE PT. BANK BCA Tbk."

[24] A. S. Putra, D. R. Aryanti, and I. Hartati, "Metode SAW (Simple Additive Weighting) sebagai Sistem Pendukung Keputusan Guru Berprestasi (Studi Kasus: SMK Global Surya)," in Prosiding Seminar Nasional Darmajaya, 2018, vol. 1, no. 1, pp. 85-97.

[25] A. S. Putra and O. M. Febriani, "Knowledge Management Online Application in PDAM Lampung Province," in Prosiding International conference on Information 
Technology and Business (ICITB), 2018, pp. 181-187.

[26] A. S. Putra, O. M. Febriani, and B. Bachry, "Implementasi Genetic Fuzzy System Untuk Mengidentifikasi Hasil Curian Kendaraan Bermotor Di Polda Lampung," SIMADA (Jurnal Sist. Inf. dan Manaj. Basis Data), vol. 1, no. 1, pp. 21-30, 2018.

[27] A. S. Putra, H. Sukri, and K. Zuhri, "Sistem Monitoring Realtime Jaringan Irigasi Desa (JIDES) Dengan Konsep Jaringan Sensor Nirkabel," IJEIS (Indonesian J. Electron. Instrum. Syst., vol. 8, no. 2, pp. 221-232.

[28] D. P. Sari, O. M. Febriani, and A. S. Putra, "Perancangan Sistem Informasi SDM Berprestasi pada SD Global Surya," in Prosiding Seminar Nasional Darmajaya, 2018, vol. 1, no. 1, pp. 289-294. 